\title{
A widespread problem: cryptic diversity in the Libyan jird
}

Timothy C Bray ${ }^{1,2^{*}}$, Abdulaziz N Alagaili, ${ }^{1,3}$ and Nigel C Bennett ${ }^{1,2}$

\begin{abstract}
Background: The Libyan jird, Meriones libycus, is described as occurring from Morocco to the Mongolian plateau. Three subspecies are known from morphological determinations but not genetic data. We used museum collection locations to create a niche model of the most likely suitable habitat for this species within its potential extent. Using samples collected from the Kingdom of Saudi Arabia, we examined genetic diversity including available samples from China and Tunisia, providing the first genetic overview of this species.

Results: Mitochondrial cytochrome $b$ data showed that genetic differentiation between Arabian and other sampling locations of M. libycus is less than the lineage separation seen in Meriones meridianus and greater than that in Meriones tamariscinus. The Arabian lineage investigated here is clearly distinct from the Chinese Meriones libycus erythrourus and Tunisian Meriones libycus syrius, the latter subspecies being previously suggested to occur in the sampling area.
\end{abstract}

Conclusions: We suggest further investigation to ascertain whether the lineage represented here is Arabian Meriones libycus arimalius or a different lineage entirely. We further question the reliability of previous morphological descriptions for producing specific determinations in Meriones and related taxa.

Keywords: Arabia; Meriones libycus; Phylogenetics; Rodent

\section{Background}

Much mammalian nomenclature has remained since pre-molecular classifications based on pelage and other morphology as well as limited information about ecology and distribution. Distinction between similar species can be problematic, particularly in arid habitats where colouration and habits are restricted and are more likely to converge on similar solutions. When the isolation of lineages does occur, it is typically gradual in nature, and contingent on levels of gene flow (Nosil 2008) with speciation processes being identifiable through genetic and morphological approaches (e.g. Jansen van Rensburg et al. 2012; Ryan et al. 2007). Pulses of speciation events are also seen (Erwin 1983) particularly in speciose genera such as murids (Conrad and Cook 1999), complicating species relationships. Convoluted patterns of lineage separation

\footnotetext{
* Correspondence: tim_c_bray@hotmail.com

${ }^{1}$ KSU Mammals Research Chair, Department of Zoology, King Saud University, Riyadh 11451, Saudi Arabia

${ }^{2}$ Department of Zoology and Entomology, University of Pretoria, Pretoria, South Africa

Full list of author information is available at the end of the article
}

have led to the term 'species complex' which often best describes these macro-spatial dynamics where clear species delimitation is problematic (e.g. Eurasian distribution of Pipistrelles; Hulva et al. 2004). It is therefore essential to consider molecular relationships in the context of other information such as distribution. With the additional data on environmental conditions, further insight into habitat requirements and preferences of an organism can be gained (Phillips 2006).

Ecological niches are suggested to present long-term constraints on species' distribution (Martinez-Meyer et al. 2004). Distribution information is often based on few collected samples or sightings, but novel methods are facilitating predictions of range extents based on ecological data (Pearson et al. 2006). Modeling species requirements in a predictive context has become a useful tool in directing conservation science (e.g. Schwartz 2012). Part of knowing a species distribution involves understanding the dynamics of the organism, extending into the understanding of demography and dispersal (Schurr et al. 2012). As such, differential patterns of habitat suitability shown through a niche modeling approach might potentially identify

\section{实}


geographic (and hence phylogenetic) discontinuities. An interesting biogeographic region for this reason is the Arabian Peninsula, the northern base of which connects with both Africa and Asia, exhibiting wide variation in habitat across its width. Although historical conditions of the Arabian Peninsula were once moist (e.g. hippopotamus remains have been found in the Rub al' Kali desert in Saudi Arabia; Holm 1960), current conditions reflect a recent arid trajectory since the early Holocene (Engel et al. 2012). Alongside diminished terrestrial connections to the other continents (e.g. from Africa into southern Arabia; Delany 2008), the peninsula has proven a fertile land for the isolation and subsequent evolution of unique lineages, and high levels of endemism are seen across a number of taxonomic groups (Mallon 2011). This Arabian habitat discontinuity is reflected in niche models (Colaccico et al. 2010), yet many species exist whose range overlaps this entire region from Africa into Asia (Harrison and Bates 1991).

The vast majority of mammalian species are not widespread, with range extents affected by trends according to latitude and species density (Pagel et al. 1991); if range is inversely related to species density in this way it may be expected that those species found in arid regions, typically occupied by relatively few species, might have comparatively wide distributions. Even if this is the case, some desertdwelling species are described as occurring over unusually large regions; The Libyan jird, Meriones libycus Lichtenstein (1823), is one such species, recorded as present from Morocco to the Mongolian Plateau (IUCN International Union for Conservation of Nature 2009; type locality 'Libyan desert'). There has been suggestion that $M$. libycus exists as subspecies either side of the Euphrates (West = Meriones libycus syrius; East $=$ Meriones libycus erythrourus), with a further putative subspecies in Saudi Arabia and Oman (Meriones libycus arimalius; Harrison and Bates 1991). Pavlinov et al. (1990) distinguish Meriones arimalius as its own species designation as does Zhang et al. (1997) for Meriones erythrourus. But no genetic evidence has yet been presented for these designations, and Wilson and Reeder (2005) regarded $M$. erythrourus as a synonym for $M$. libycus. The explanation of this wide range of a single species likely lies in the fact that many taxonomic relationships between rodent taxa are uncertain. Superfamily Muroidea contains over a quarter of all mammal species (e.g. Chevret and Dobigny 2005), and diversity in these overlooked genera is often undescribed. Current interest in species such as $M$. libycus are based on its response to environmental variables (e.g. desert adaptation (Belhocine et al. 2007), pollution (Adham et al. 2011), and potential importance as a host for various zoonotic diseases (Rassi et al. 2006, Yavar et al. 2011)). Unravelling the level, direction, and limits of gene flow and the resultant partitioning of sub-species (and even full species) is likely to be highly influential in these areas of study.

The purpose of this study is to determine whether morphological similarity and lack of data have resulted in the current seemingly 'blanket' determinations for Meriones species, with particular consideration of $M$. libycus. Using a niche modelling approach, we make an approximation of habitat suitability of $M$. libycus across its described range. Using available cytochrome $b$ sequence data and individuals sampled in this study, we make genetic comparisons between two widely separated geographic locations in this species and the subspecies M. $l$. erythrourus, and place this in the context of other Meriones taxa. Specifically, we ask the following: (1) Does the described range encompass a continuous stretch of suitable habitat, or is it possible to identify regions of isolated habitat likely to show similar genetic isolation, such as the Arabian Peninsula? (2) Is the genetic variation seen in $M$. libycus consistent with that found within other Meriones species? (3) What are the conservation implications of the results from the niche modelling and the genetic diversity for conservation management?

\section{Methods}

\section{Ethics statement}

Ethical approval for this study was given by the Animal Use and Care Committee of the University of Pretoria under project number EC046-1. Permission for sample collection was granted by the Saudi Wildlife Authority.

\section{Niche modelling}

Geographic coordinates were taken from the IUCN species database for 112 separate Meriones libycus sample locations (IUCN International Union for Conservation of Nature 2009; see Figure 1). To avoid confounded location condition data, a 10-km minimum was imposed on sample proximity.

The niche modelling approach was performed through the MAXENT (Phillips 2006) approach. An initial test model was run for all 19 Worldclim bioclimatic variables (WorldClim 2011; Additional file 1) as well as altitude and ecosystem land cover (USGS 2008). In accordance with the appropriate use of explanatory variables (Warren and Seifert 2011), those with the lowest contribution to the model $(<1 \%)$ were excluded (bioclimatic variables $2,5,7$, $10,13,14,15$, and altitude). The remaining 13 variable layers (bioclimatic variables $1,3,4,6,8,9,11,12,16$, $17,18,19$, and land cover) were then used to make a predictive model of occurrence (area considered lat/long; $40.51,-15.03$ to $11.70,74.36)$. Ten iterations of the model were run under the cross-validation setting. Mean area under the curve (AUC) and variable influence were calculated for the model. Inferences of suitable habitat were used to predict occurrence probability 


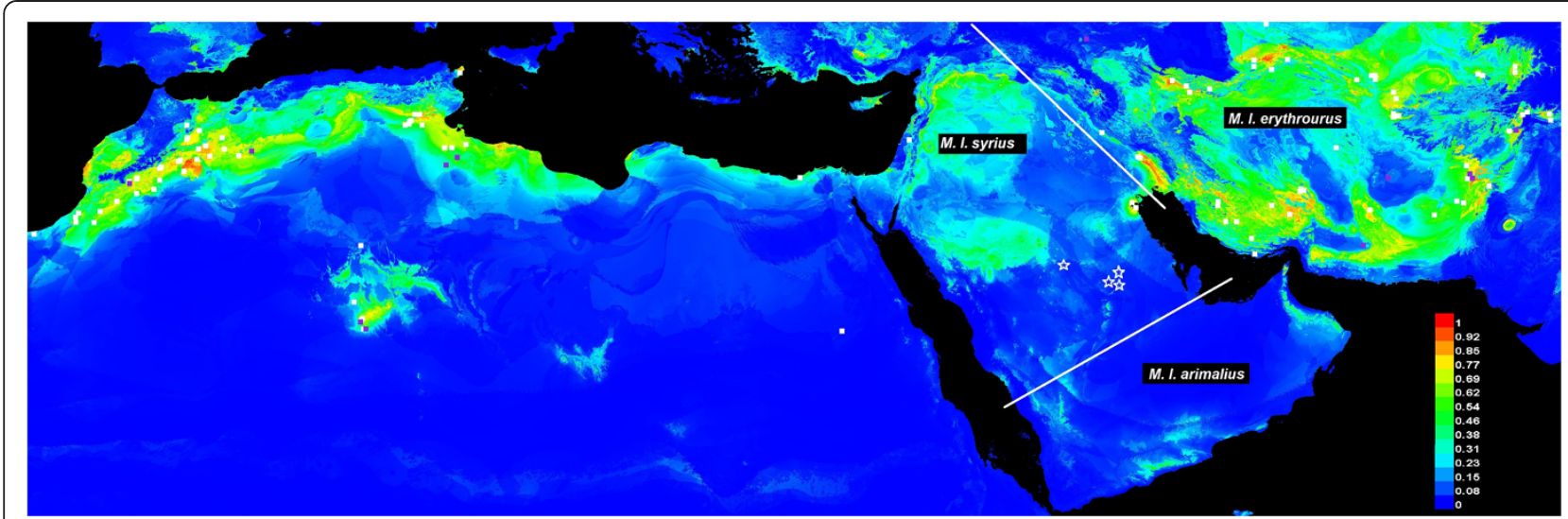

Figure 1 Ecological niche model of distribution of majority of documented range of Meriones libycus (probability-of-occurrence key lower right). Red solid boxes indicate the highest probability of occurrence, dark blue ones indicate the lowest. Sample locations are shown as squares for training (white) and test (purple) conditions. Arabian M. libycus sample locations are marked as white stars. Previously suggested sub-specific limitations (according to Harrison and Bates 1991) are marked as white lines.

with $90 \%$ of the presence data used to train the model.

\section{Genetic sampling, sequencing, and phylogenetic analysis}

Samples were collected from three sites in and around Riyadh city and from a location of approximately 300 $\mathrm{km}$ to the west, in the Kingdom of Saudi Arabia (Figure 1). DNA extraction was performed from earlobe tissue using Qiagen extraction reagents and separate spin columns (Epoch Life Science, Missouri City, TX, USA). The mitochondrial cytochrome $b$ (cytb) gene was amplified using the L15162 (Irwin et al. 1991) and CytbLibR (5'-TTGTCCTCAATGATTCCTCGA-3', designed for this study). The nuclear recombination activating gene 2 (RAG2) was amplified using F1INT/R1 primers (Baker et al. 2000). PCR was run for a single cycle of $3 \mathrm{~min}$ at $94^{\circ} \mathrm{C}$ with 40 cycles comprising denaturing at $94^{\circ} \mathrm{C}$ for $30 \mathrm{~s}$, annealing at $48 / 50^{\circ} \mathrm{C}$ for $30 \mathrm{~s}$, and extension at $72^{\circ} \mathrm{C}$ for $45 \mathrm{~s}$. Reverse sequences were generated for confirmation. Sequence data was cleaned and aligned in BioEdit (Hall 2005) and combined with samples already available. Nucleotide substitutions and translation into amino acids was performed through MEGA5 (Tamura et al. 2011). The most appropriate nucleotide substitution model to apply for the subsequent analyses was determined according to the Akaike Information Criterion (AIC; Akaike 1974) using JMODELTEST (Posada 2008). Neighbour joining trees were constructed and compared between gene regions separately using MEGA5. The supports for the phylogenetic relationships obtained by the neighbour-joining method were evaluated by the bootstrap analysis (1,000 replicates). Maximum parsimony haplotype networks were calculated using the TCS (Clement et al. 2000) application. The application TCS was used to draw parallel haplotype networks from the cytb data in M. libycus, Meriones meridianus, and Meriones tamariscinus.

\section{Molecular dating}

Time since divergence of all available Meriones species, as well as all geographically separate $M$. libycus lineages were calculated using sequence data through the BEAST application (Drummond and Rambaut 2007). Both species models (Yule; Birth-death) were tested in addition to all options for the clock models (Strict, Relaxed lognormal, Relaxed exponential, and Random local), with likelihoods compared in Tracerv1.5 (Rambaut and Drummond 2007) over $1 \times 10^{8}$ iterations. The model with the highest likelihood was run for $1 \times 10^{9}$ iterations (sampling every $1 \times 10^{5}$ with $10 \%$ burn-in samples removed). The molecular clock was calibrated using the fossil-dated split between Mus and Rattus of 16 million years ago (mya; normal distribution, $\mathrm{SD}=1.5$ ) as calculated by an averaging approach across multiple calibration points (Douzery et al. 2003). Due to the low reliability of the fossil record within Gerbillinae, no additional internal calibration point could be used in our analysis (Tong 1989). To improve the accuracy of the dating approach, we compared both mitochondrial cytb and nuclear RAG2 genes for common nodes.

\section{Results}

\section{Niche modelling}

The final model describing the occurrence of $M$. libycus gave a mean AUC of $0.89(\mathrm{SD}=0.05)$. The greatest parameter contribution was precipitation of the coldest quarter (e.g. the driest season in the Arabian Peninsula) which had an optimum range of 0 to $20 \mathrm{~mm}$. The least contribution was made by the land cover classification. To identify whether discontinuities in occurrence probability 
corresponded with described subspecies limitations (Harrison and Bates 1991), these were compared with the results of the niche model (Figure 1).

\section{Sequence characteristics and phylogenetic analysis}

A total of 941 bp of cytb and 836 bp of RAG2 sequence data were generated for 15 and 21 individuals, respectively. Within the Arabian M. libycus, eight haplotypes were determined from cytb with nucleotide diversity in cytb of 0.004 and 8 parsimony informative sites. A single haplotype was identified in the Arabian RAG2 gene. Sequence data were combined with both cytb and RAG2 sequences already available (sequence details and accession numbers in Table 1). The most appropriate mutational models were determined to be TIM with invariable sites for cytb and TIM3 for RAG2 (-ln likelihoods 4621 and 2716, respectively). A neighbour joining cytb tree showed strong support $(\geq 97 \%$ consensus bootstrap support) for three lineages within $M$. libycus (Additional file 2: Figure S1). The maximum parsimony haplotype network showed that the Arabian cytb haplogroup is 49 substitutions distant from the closer Chinese $M$. $l$. erythrourus which is then nine substitutions distant from the Tunisian Meriones libycus libycus (Figure 2). The haplotype networks for each of the Meriones species $M$. libycus, $M$. meridianus, and $M$. tamariscinus were constructed for comparison (Figure 2). Statistical parsimony analysis using a 95\% connection limit resulted in the separation of all nodes above 15 substitutions into separate subnetworks. Extending the connection limits to 100 substitutions allowed the substitutional distances between subnetworks to be shown.

\section{Molecular dating}

For the Drummond and Rambaut (2007) approach, the highest likelihood for cytb was obtained from the Birth-death model using a random local clock, and for the RAG2 was the Yule species model, using a strict molecular clock. Dating comparisons between genes of the Meriones libycus/unguiculatus split, showed a more ancient estimate for the cytb gene compared to RAG2 with median values of 8.3 and 4.6 mya ( $95 \%$ confidence interval $(\mathrm{CI})=5.5$ to 11.6 and 1.0 to 5.3 , respectively; Figure 3). Within M. libycus, the cytb estimate of divergence for the Arabian lineage was 3.2 mya ( $95 \% \mathrm{CI}=1.9$ to 4.7 ), and between the Tunisian and Chinese $M$. l. erythrourus estimated at 0.38 mya ( $95 \% \mathrm{CI}=0.15$ to 0.67 ).

\section{Discussion}

Range and habitat continuity in the Libyan jird

The application of niche modeling in this case was intended to both identify a correspondence between the suggested range of $M$. libycus (IUCN International Union for Conservation of Nature 2009), and identify if range breaks aligned with described subspecies limitations (Harrison and Bates 1991). The resultant map shows that there are no strong habitat breaks that might be used to explain previously hypothesised subspecies

Table 1 Sample details and GENBANK accession numbers for cytochrome $b$ and rhodopsin activating (2) gene

\begin{tabular}{|c|c|c|c|c|}
\hline Species & NCytb / NRAG2 & Sample origin & GenBank Cytb / RAG2 & Reference \\
\hline M. libycus & $2 / 4$ & $\begin{array}{l}\text { Saudi Arabia1 } \\
(24.999,46.821)\end{array}$ & KC480077 / KC480070 & This study \\
\hline M. libycus & $2 / 3$ & $\begin{array}{l}\text { Saudi Arabia2 } \\
(25.950,43.953)\end{array}$ & KC480083 / KC480071 & This study \\
\hline M. libycus & $3 / 5$ & $\begin{array}{l}\text { Saudi Arabia3 } \\
(25.115,46.101)\end{array}$ & KC480081, KC480082 KC480084 / KC480072 & This study \\
\hline M. libycus & $8 / 9$ & $\begin{array}{l}\text { Saudi Arabia4 } \\
(25.220,46.632)\end{array}$ & $\begin{array}{c}\text { KC480078, KC480079, KC480080, } \\
\text { KC480084 / KC480074 }\end{array}$ & This study \\
\hline M. libycus & $1 /-$ & China, Turfan & AB381902 & Ito et al. (2010) \\
\hline M. libycus & $9 /-$ & Tunisia & JQ927404-JQ927412 & Unpublished \\
\hline M. chengi & $1 /-$ & China & AB381900 & Ito et al. 2010 \\
\hline M. crassus & $1 /-$ & Saudi Arabia & AJ851267 & Chevret and Dobigny 2005 \\
\hline M. meridianus & $6 /-$ & China & AB381894-AB381899 & Ito et al. 2010 \\
\hline M. tamariscinus & $28 /-$ & China & AB381904-AB381906, JN604750-JN604781 & Ito et al. 2010; Gu et al. 2011 \\
\hline M. rex & $1 /-$ & Saudi Arabia & AJ851265 & Chevret and Dobigny 2005 \\
\hline M. unguiculatus & $1 / 1$ & China & AF159405 / FN984756 & Conrad and Cook 1999 / Edrey et al. 2012 \\
\hline Gerbillus dasyurus & $-/ 1$ & Israel & FM162087 & Blanga-Kanfi et al. 2009 \\
\hline Gerbillus nanus & $1 /-$ & Pakistan & JQ753063 & Ndiaye et al. 2012 \\
\hline Mus musculus & $1 / 1$ & - & AY057804 & Lundrigan et al. 2002 / Ruppert et al. 2012 \\
\hline Rattus norvegicus & $1 / 1$ & - & FR775888 & Balakirev and Rozhnov 2012 / DeBry 2003 \\
\hline
\end{tabular}




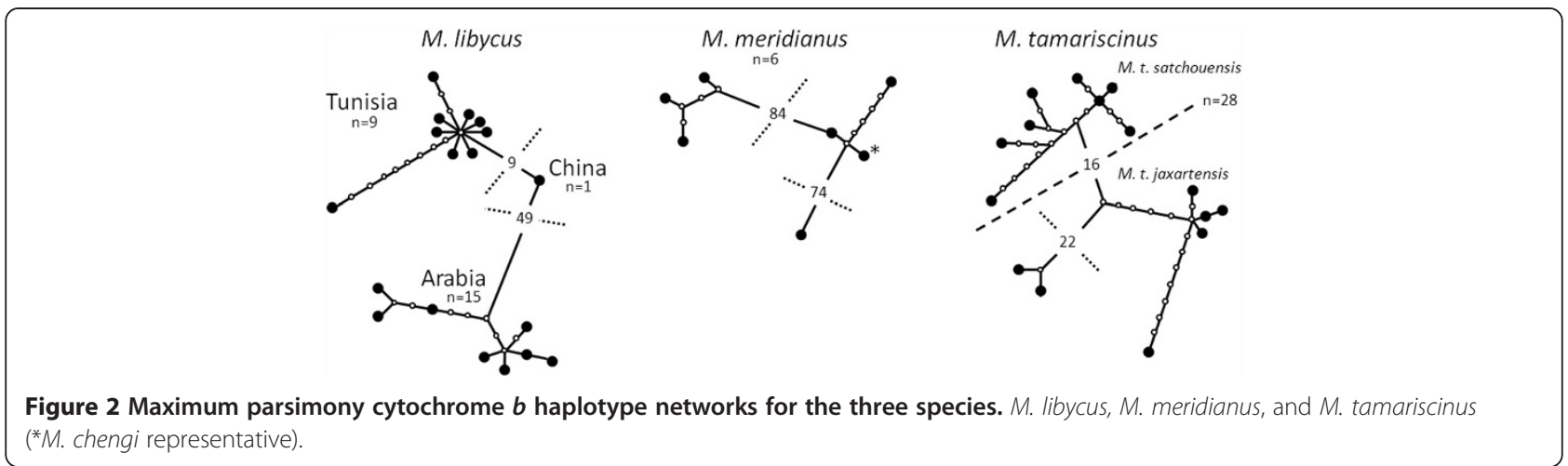

delimitations between $M . l$. syrius and $M . \quad l$. erythrourus (Figure 1). The riparian system of the Euphrates would have provided continuous habitat with opportunities for rafting when the river was in spate, as proposed for other murids (Prager et al. 1998). A widespread of continuous habitat is seen from Morocco to China, with some narrowing through Libya and Egypt. The model identifies good potential for isolated suitable habitat in south eastern Algeria and to a lesser extent in northern Chad. Some habitat discontinuity also exists within the Arabian Peninsula, with a decrease in suitability towards the southern extent. There appears to be a very weak correspondence of the niche model to available habitat in the mid to lower Arabian Peninsula, particularly in the region corresponding to the area of occurrence of $M$. $l$. arimalius. This would be the case if $M$. l. arimalius was occupying a narrower set of environmental conditions than those on which the niche model was based. Such a case might be expected if heterogeneity of available habitat was restricted, promoting specialisation for narrow preference ranges accordingly (Gilchrist 1995).

\section{Intra-specific variation in Meriones species}

The cytochrome $b$ data demonstrated strong stratification within M. libycus according to geographic origin. Despite a greater proximity between Tunisia and Arabia, these locations were the most genetically distant $(>5.2 \%$ substitutions), the former being far closer to the Chinese representative ( $>1.0 \%$ substitutions). To test the hypothesis that $M$. libycus exists as a single widely distributed species, we compared it with two other available Meriones species, M. meridianus and M. tamariscinus (Figure 2). Despite M. libycus being from the most geographically disparate sample locations of the three species, the Arabian/Tunisian split displayed intermediate differentiation relative to haplogroup differentiation in the other species. The work of $\mathrm{Gu}$ et al. (2011) described their recommendation for sub-specific allocation based on the lineage separation within $M$. tamariscinus (1.4\% substitutions). Similarly, Ito et al. (2010) recommend the elevation of haplogroups in $M$. meridianus to sub-specific or even up to specific status $(6.7 \%$ and $7.5 \%$ substitutions). The division into sub-networks at $95 \%$ probability has been proposed as evidence for cryptic species diversity (Hart and Sunday 2007), and is seen here for all divisions above 15 substitutions. This approach supports an additional division within $M$. tamariscinus, but not a division within M. libycus between Chinese and Tunisian locations. It is important to note that previous species allocation in

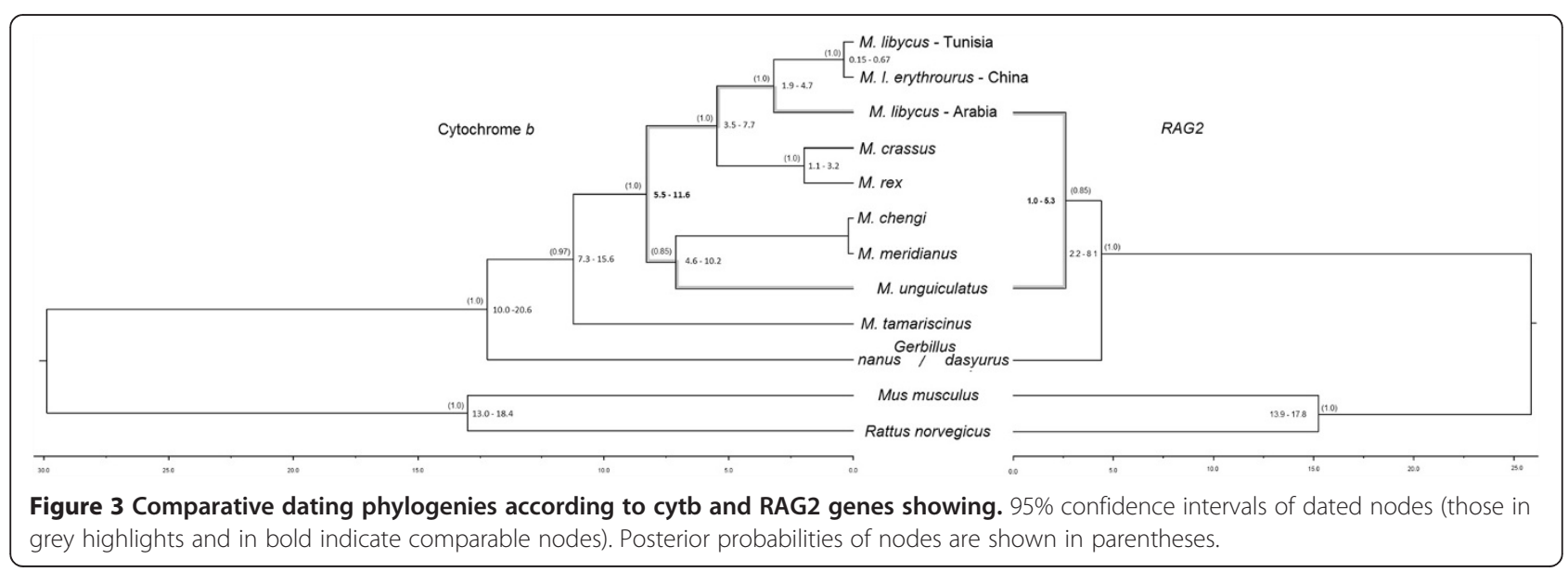


Meriones was based on morphological characters, and Ito et al. (2010) undermine this approach by showing the presence of 'Meriones chengi' within M. meridianus as being merely a divergent colour morph. The literature suggested that all M. libycus found to the west of the Euphrates and above the southern Arabian break determined for $M$. $l$. arimalius, is the subspecies $M$. $l$. syrius (Harrison and Bates 1991). The evidence for the Chinese and Tunisian populations being separate subspecies is weak based on the data shown in this study. The Arabian samples in this study are clearly genetically distinct from the Tunisian $M$. $l$. syrius in contradiction of the IUCN (International Union for Conservation of Nature) (2009) distribution database and Harrison and Bates (1991). It is unknown whether these Arabian individuals therefore represent $M . l$. arimalius, or if there is even further genetic variation to be discovered in the Arabian peninsula. The most parsimonious explanation would be that the northern range extent of $M$. $l$. arimalius was underestimated and needs to be moved northwards.

It is likely that the geographic extent of $M$. l. arimalius is greater than currently recognised and it would be interesting to know if there is indeed an isolation-by-distance relationship with more northern $M$. libycus or if a northern discontinuity occurs, as indicated by the niche model, towards the base of the peninsula. The clearly distinctive genetic composition of the Arabian haplogroup currently suggests comparable differentiation to other small mammals at a full-species level (e.g. Microtus voles, $4.2 \%$ to $5.7 \%$ substitutions; (Krystufek et al. 2009). This is further supported by the molecular dating for the cytb gene which gives a median estimate of the Arabian split as 3.2 mya, although comparable nodes in the RAG2 gene tree are more conservative, suggesting that this value may be as low as approximately 1.6 mya. This is comparable to the speciation rates for other rodent taxa; the per lineage diversification rates in Rattus have been estimated at up to 3.0 per million years (Rowe et al. 2011). Qualitatively speaking, this divergence within $M$. libycus predates the Meriones crassus/Meriones rex divergence. The Arabian representatives shown here represent a clearly distinct lineage separate from $M$. libycus elsewhere. More extensive sample coverage is necessary before taxonomic reorganisation is considered. Closer consideration of these species is likely to also be accompanied by complete reorganisation of the potentially paraphyletic Meriones group (see Ito et al. 2010).

\section{Conservation implications of diversity in the Libyan jird}

There are currently 17 species of jird recognised by the IUCN Red list (2011). The genetic distinction of the Arabian M. libycus lineage suggests that it should be considered separately from the lineages present in the other regions. Where this genetic distinction represents local specialisation to sandy conditions as suggested by
Harrison and Bates 1991(M. l. arimalius) is unknown. Behavioural data do support Arabian M. libycus being specialised relative to $M$. rex, through exhibition of more narrow responses to changes in the circadian rhythm (Alagaili et al. 2013), which may explain the magnitude of divergence from other M. libycus. Although there is no evidence for a general decline of $M$. libycus, Meriones species are known as agricultural pests and as such are subject to persecution (e.g. Mian et al. 1988). Whatever the taxonomic designation of Saudi Arabian M. libycus (arimalius), it represents a unique genetic entity and therefore of notable conservation value.

\section{Conclusions}

Whilst being clear that finer scale sampling could add to the consideration of $M$. libycus, we showed that even without this, we can begin to gain insight into such species using niche modelling and genetic techniques. We show the need for genetic characterisation of M. libycus, as is required in the other jird species mentioned here. We conclude that necessary as they were initially, we have transcended the need for 'blanket' morphological species descriptions and can begin to look at the well-established genetic marker regions for help in redefining both genealogical and geographical boundaries within Meriones. We also associate the putatively unsuitable habitat moving down into, and including, the Arabian Peninsula with the high separation between the Saudi Arabian and other $M$. libycus. The most important environmental variable in the niche model was precipitation in the coldest quarter. Only by identification of each evolutionarily significant unit can any conservation measures really be considered and applied. Once these units are defined, their ecology, range, and persistence will begin to reveal whether there are vulnerabilities associated with their habitat utilisation and the process of conservation management can begin.

\section{Additional files}

Additional file 1: List of Worldclim bioclimatic variables as used in the niche model (1), Average omission and predicted area (2), Jackknife of AUC (3).

Additional file 2: Figure S1. Consensus neighbour joining phylogeny of the cytochrome $b$ gene for all available Meriones species.

\section{Competing interests}

The authors declare that they have no competing interests.

\section{Authors' contributions}

TB and NB conceived the design and implementation of the study and helped to draft the manuscript. NB provided ethical clearance and permissions for non-destructive sampling. AA conducted sampling, including permissions from Saudi Arabian authorities, and provided research equipment and facilities. TB conducted laboratory procedures, niche modelling, and sequence analyses. All authors read and approved the final mansucript. 


\section{Acknowledgements}

Funding was provided by the Deanship of Scientific Research at the King Saud University through the research group project number RGP_VPP_020, as well as the DST-NRF SARChI Chair for Mammal behavioural ecology and physiology. O Mohammed is recognised for the design of the CytbLibR primer.

\section{Author details}

'KSU Mammals Research Chair, Department of Zoology, King Saud University, Riyadh 11451, Saudi Arabia. ${ }^{2}$ Department of Zoology and Entomology, University of Pretoria, Pretoria, South Africa. ${ }^{3}$ Saudi Wildlife Authority, Riyadh 11575, Saudi Arabia.

\section{Received: 7 October 2013 Accepted: 11 June 2014}

Published: 3 July 2014

\section{References}

Adham KG, Al-Eisa NA, Farhood MH (2011) Risk assessment of heavy metal contamination in soil and wild Libyan jird Meriones libycus in Riyadh, Saudi Arabia. J Environ Biol 32:813-819

Akaike H (1974) A new look at the statistical model identification. IEEE T Automat Control 19:716-723

Alagaili AN, Mohammed OB, Bennett NC, Oosthuizen MK (2013) A tale of two jirds: the locomotory activity patterns of the King jird (Meriones rex) and Libyan jird (Meriones libycus) from Saudi Arabia. J Arid Environ 88:102-112

Baker RJ, Porter CA, Patton JC, Van Den Busche RA (2000) Systematics of bats of the family Phyllostomidae based on RAG2 DNA sequences. Occas Pap Mus Texas Tech Univ 202:1-16

Balakirev AE, Rozhnov W (2012) Contribution to the species composition and taxonomic status of some Rattus inhabiting southern Vietnam and Sundaland. Russ J Therio 11(1):33-45

Belhocine M, Genigon-Spychalowicz T, Robert AM, Schoevaert D, Bennazzoug Y, Exbrayat JM (2007) Ecophysiological responses of the seminal vesicle of Libyan jird (Meriones libycus) to the Saharan conditions: histological, morphometric and immunohistochemical analysis. Histol Histopathol 22:603-615

Blanga-Kanfi S, Miranda H, Penn O, Pupko T, DeBry RW, Huchon D (2009) Rodent phylogeny revised: analysis of six nuclear genes from all major rodent clades. BMC Evol Biol 9:71

Chevret P, Dobigny G (2005) Systematics and evolution of the subfamily Gerbillinae (Mammalia, Rodentia, Muridae). Mol Phylogenet Evol 35:674-688

Clement M, Posada D, Crandall KA (2000) TCS: a computer program to estimate gene genealogies. Mol Ecol 9:1657-1660

Colaccico MG, Masuoka PM, Grieco JP (2010) Ecological niche model of Phlebotomus alexandri and P. papatasi (Diptera: Psychodidae) in the Middle East. Int J Health Geogr 9:3-9

Conrad CJ, Cook JA (1999) MtDNA evidence for repeated pulses of speciation within arvicoline and murid rodents. J Mamm Evol 6:221-245

DeBry RW (2003) Identifying conflicting signal in a multigene analysis reveals a highly resolved tree: the phylogeny of Rodentia (Mammalia). Syst Biol 52(5):604-617

Delany MJ (2008) The zoogeography of the mammal fauna of Southern Arabia. Mammal Rev 19:133-152

Douzery EJP, Delsuc F, Stanhope MJ, Huchon D (2003) Local molecular clocks in three nuclear genes: divergence times for rodents and other mammals and incompatibility among fossil calibrations. J Mol Evol 57:S201-\$213

Drummond AJ, Rambaut A (2007) BEAST: Bayesian evolutionary analysis by sampling trees. BMC Evol Biol 7:214

Edrey YH, Casper D, Huchon D, Mele J, Gelfond JA, Kristan DM, Nevo E, Buffenstein R (2012) Sustained high levels of neuregulin-1 in the longest-lived rodents; a key determinant of rodent longevity. Aging Cell 11(2):213-222

Engel M, Bruckner H, Pint A, Wellbrock K, Ginau A, Voss P, Grottker M, Klasen N, Frenzel P (2012) The early Holocene humid period in NW Saudi Arabia - sediments, microfossils and palaeo-hydrological modeling. Quatern Int 266:131-141

Erwin TL (1983) The taxon pulse: a general pattern of lineage radiation and extinction among carabid beetles. In: Ball GE (ed) Taxonomy, Phylogeny, and Zoogeography of Beetles and Ants. Springer, New York

Gilchrist GW (1995) Specialists and generalists in changing environments. I. Fitness landscapes of thermal sensitivity. Am Nat 146:252-270
Gu D, Zhou L, Ma Y, Ning S, Hou Y, Zhang B (2011) Geographic variation in mitochondrial DNA sequences and subspecies divergence of the Tamarisk Gerbil (Meriones tamariscinus) in China. Acta Theriol Sin 31:347-357

Hall T (2005) BioEdit v 7.0.5., http://www.mbio.ncsu.edu/BioEdit/bioedit.html. Accessed, 19 Sept 2012

Harrison DL, Bates PJJ (1991) The mammals of Arabia. Ernest Benn Limited, London

Hart MW, Sunday J (2007) Things fall apart: biological species form unconnected parsimony networks. Biol Lett 3(5):509-512

Holm DA (1960) Desert geomorphology in the Arabian peninsula. Science 3437:1369-1379

Hulva P, Horacek I, Strelkov PP, Benda P (2004) Molecular architecture of Pipistrellus pipistrellus/Pipistrellus pygmaeus complex (Chiroptera: Verspertilionidae): further cryptic species and Mediterranean origin of the divergence. Mol Phylogenet Evol 32:1023-1035

Irwin DM, Kocher TD, Wilson AC (1991) Evolution of the cytochrome b gene of mammals. J Mol Evol 32:128-144

Ito M, Jiang W, Sato JJ, Zhen Q, Jiao W, Goto K, Sato H, Ishiwata K, Oku Y, Chai JJ, Kamiya H (2010) Molecular phylogeny of the subfamily Gerbillinae (Muridae, Rodentia) with emphasis on species living in the Xinjiang-Uygur Autonomous Region of China and based on the mitochondrial Cytochrome b and Cytochrome c Oxidase subunit II genes. Zool Sci 27:269-278

IUCN (International Union for Conservation of Nature) (2009) Meriones libycus. In: IUCN 2011. IUCN Red List of Threatened Species. Version 2011.2., http://www. iucnredlist.org/info/faq\#Using_RL_data. Accessed, 23 Apr 2011

Jansen van Rensburg A, Bloomer P, Ryan PG, Hansson B (2012) Ancestral polymorphism at the major histocompatibility complex $(\mathrm{MHCl} \beta)$ in the Nesospiza bunting species complex and its sister species (Rowettia goughensis). BMC Evol Biol 12:143

Krystufek B, Buzan EV, Vohralik V, Zareie R, Ozkan B (2009) Mitochondrial cytochrome b sequence yields new insight into the speciation of social voles in south-west Asia. Biol J Linn Soc 98:121-128

Lichtenstein H (1823) Über die Springmäuse oder die Arten der Gattung Dipus. Abh der K Akad Wiss 1825:133-162

Lundrigan BL, Jansa SA, Tucker PK (2002) Phylogenetic relationships in the genus mus, based on paternally, maternally, and biparentally inherited characters. Syst Biol 51(3):410-431

Mallon DP (2011) Global hotspots in the Arabian peninsula. Zool Middle East Suppl 3:13-20

Martinez-Meyer E, Peterson AT, Hargrove WW (2004) Ecological niches as stable distributional constraints on mammal species, with implications for Pleistocene extinctions and climate change projections for biodiversity. Global Ecol Biogeogr 13:305-314

Mian A, Ali M, Ali R, Tousif SB (1988) Distribution of some mammalian pests of orchards in Baluchistan. Pakistan J Agric Res 9:125-130

Ndiaye A, Shanas U, Pascale C, Granjon L (2012) Molecular variation and chromosomal stability within Gerbillus nanus (Rodentia, Gerbillinae): taxonomic and biogeographic implications. Mammalia 0:1-7

Nosil P (2008) Speciation with gene flow could be common. Mol Ecol 17:2103-2106

Pagel MD, May RM, Collie AR (1991) Ecological aspects of the geographical distribution and diversity of mammalian species. Am Nat 137:791-815

Pavlinov I, Yu Y, Dubrovsky A, Rossolimo OL, Potapova EG (1990) Gerbils of the world. Nauka, Moscow, p 368

Pearson RG, Thuiller W, Araújo MB, Martinez-Meyer E, Brotons L, McClean C, Miles L, Segurado P, Dawson TP, Lees DC (2006) Model-based uncertainty in species range prediction. J Biogeogr 33:1704-1711

Phillips SJ (2006) Maxent Software for Species Habitat Modeling, ver. 2.0., p 2, http://www.cs.princeton.edu/ schapire/maxent/. Accessed, 23 Jan 2012

Posada D (2008) JMODELTEST: phylogenetic model averaging. Mol Biol Evol 25 (7):1253-1256

Prager EM, Orrego C, Sage RD (1998) Genetic variation and phylogeography of central Asian and other house mice, including a major new mitochondrial lineage in Yemen. Genetics 150:835-861

Rambaut A, Drummond AJ (2007) Tracer v1.5., Available from http://beast.bio.ed. ac.uk/software/tracer/. Accessed, 12/04/2012

Rassi Y, Javadian E, Amin M, Rafizadeh S, Vatandoost H, Motazedian H (2006) Meriones libycus is the main reservoir of zoonotic cutaneous leishmaniasis in south Islamic Republic of Iran. East Mediterr Health J 12:474-477

Rowe KC, Aplin KP, Baverstock PR, Moritz C (2011) Recent and rapid speciation with limited morphological disparity in the genus Rattus. Syst Biol 60:188-203 

govern the processes of autophagy and apoptosis in interleukin-7 dependent lymphocytes. Biochim Biophys Acta 1823(10):1877-1893

Ryan PG, Bloomer P, Moloney CL, Grant TJ, Delport W (2007) Ecological speciation in South Atlantic island finches. Science 315(5817):1420-1423

Schurr FM, Pagel J, Cabral JS, Groeneveld J, Bykova O, O'Hara RB, Hartig F, Kissling WD, Linder HP, Midgley GF, Schroder B, Singer A, Zimmermann NE (2012) How to understand species' niches and range dynamics: a demographic research agenda for biogeography. J Biogeogr 39:2146-2162

Schwartz MW (2012) Using niche models with climate projections to inform conservation management decisions. Biol Conserv 155:149-156

Tamura K, Peterson D, Peterson N, Stecher G, Nei M, Kumar S (2011) MEGA5: molecular evolutionary genetics analysis using maximum likelihood, evolutionary distance, and maximum parsimony methods. Mol Biol Evol 28:2731-2739

Tong H (1989) Origine et évolution des Gerbillidae (Mammalia, Rodentia) en Afrique du Nord. Mém Soc Géol Fr 155:1-120

USGS (2008) United States Geological Survey, Global Land Cover Characterization., http://edc2.usgs.gov/glcc/glcc.php. Accessed 20 Feb 2012

Warren DL, Seifert SN (2011) Ecological niche modeling in Maxent: the importance of model complexity and the performance of model selection criteria. Ecol Appl 21:335-342

Wilson D, Reeder D (e) (2005) Mammal species of the world: a taxonomic and geographic reference, 3rd edition. John Hopkins University Press, Baltimore

WorldClim (2011) Global Climate Data Download., http://www.worldclim.org. Accessed, 20 Feb 2012

Yavar R, Abedina S, Rezaa AM, Alia OM, Sinab R, Mehdic M, Rezaa Y-EM, Reza YE, Fatemeh M, Babak F (2011) Phlebotomus papatasi and Meriones libycus as the vector and reservoir host of cutaneous leishmaniasis in Qomrood District, Qom Province, central Iran. Asian Pac J Trop Med 4:97-100

Zhang Y, Jin S, Quan G, Li S, Ye Z, Wang F, Zhang M (1997) Distribution of mammalian species in China. China Forestry Publishing House, Beijing, 280 pp

doi:10.1186/s40555-014-0033-3

Cite this article as: Bray et al: A widespread problem: cryptic diversity in the Libyan jird. Zoological Studies 2014 53:33.

\section{Submit your manuscript to a SpringerOpen ${ }^{\circ}$ journal and benefit from:}

- Convenient online submission

- Rigorous peer review

- Immediate publication on acceptance

- Open access: articles freely available online

- High visibility within the field

- Retaining the copyright to your article

Submit your next manuscript at springeropen.com 